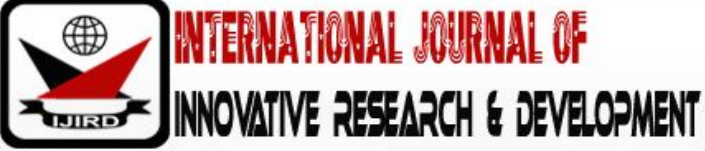

ISSN 2278 - 0211 (Online)

\section{Establishing the Need to Use Mobile Phones in Distance Learning in Ghana}

\author{
Destiny Kwabla Amenyedzi \\ Tutor, St. Francis College of Education, Hohoe, Ghana \\ Eugene Badzongoly \\ Software Engineer, Ghana Telecom University College, Ghana
}

\begin{abstract}
:
The study was to establish the use of mobile phones in distance education. It is to find out which of the mobile handsets students possess can be used for learning. This study, therefore, examined how mobile handsets or phones could be utilised in distance education to enable learners to access study materials through the use of these mobile phones. The purpose of the study was to develop an application that could be used by students to access distance learning materials on their mobile phones for study so that they would be able to learn anytime and anywhere. Hypertext Preprocessor (PHP) was used in the development of the application for the mobile phones. The application was deployed on a network for students to access with their mobile handsets. The network had a WAMP server onto which the mobile application was installed to provide the web services. After the application was pre-tested, forty students selected at random for the study used four classes of mobile phones (LG-P350, Nokia C3, Samsung galaxy pocket and TecnoN3/ P3 mobile phones) to request for the material from the WAMP server. The results of the study showed that the LG-P350, Nokia C3, Samsung galaxy pocket and TecnoN3/ P3 mobile phones were able to access the 184kb study material with the four classes of phones. Hence, these classes of mobile phones were found to be useful in the delivery of lecture notes to distance learners in this global village we live. The study also revealed that a statistically significant difference existed between the time taken to download the study material from the mobile application and through Short Messaging Service (SMS) .
\end{abstract}

Keywords: Mobile learning, mobile application

\section{Introduction}

Education, in Ghana today, has become so important that anyone without the requisite qualification in formal education feels so bad about how society treats him/her. Though the demand for tertiary education is becoming high, access to these institutions is low because these institutions are inadequate. Moreover, our classrooms are not enough to contain learners.

In the attempt to find practical solutions to these problems in order that people can have access to tertiary education, much hope has been placed on distance education. New information and communication technologies (ICTs) have been developed which can empower teachers and learners by facilitating communication and interaction, offering new modes of delivery, and generally transforming teaching and learning processes. Of the many different forms of ICTs, mobile phones are thought, for several reasons to be a suitable tool for advancing education in developing countries. Mobile phones are the most prevalent ICT in the developing world, and the penetration rate is rising rapidly.

Advanced mobile devices such as "smart" cellular telephones are very popular among people primarily because they are wireless and portable. These functionalities enable users to communicate while on the move. The popularity of these devices is, therefore, a consequent of their ability to function at multiple levels. Moreover, the intense commercial competitiveness in the mobile device industry is forcing manufacturers to be very innovative, constantly striving to introduce new features that can give them a competitive edge.

Against this backdrop, visionary educators, designers and developers should begin to consider the implications of these devices for the modern teaching and learning environment. In such an environment, contents and services can be relayed to a university or tertiary education student by personal wireless mobile devices. This will add another layer to the personal computer-based model of teaching and learning. This also means m-learning will take place in conditions that will be radically different from those educators and learners are familiar with.

In Ghana, mobile phones are common technological tool that can be found in every household one can think of. In addition to voice communication, mobile phones allow the transfer of data, which can be particularly useful for delivering educational content over long distances. The trend today, is young men and women of Ghana use a lot more mobile devices such as ipads, galaxy tabs, kindles, tablets PCs, Netbooks and the like for their day to day activities. Mobile phone has found a place as a permanent companion of the poor and the rich. It is no longer a device for showing off one's prowess in 
terms of his/ her richness (Muyinda, 2007). It is clear that mobile devices are now the way to go and learning in the classroom as well as outside the classroom is not an exception. It has become necessary, therefore, to encourage mobile learning (m-learning) in our institutions more especially in the higher educational sectors.

Mobile learning is a new technological way of learning and is being reviewed every now and then. Mobile learning can be described as learning activities that take place with the assistance of mobile devices. Traxler (2003) defined mobile learning as any educational provision where the sole or dominant technologies are handheld or palmtop devices. The introduction of mobile devices in learning is to avoid traditional lecture-based education methods and face-to-face interaction in the classroom (Ryu and Parsons, 2008). Research has shown that a majority of students in institutions of higher education as well as students on higher education distance programmes possessed computing devices, smartphones, personal digital assistants and other devices which they could use for communication. However, it was found that the use of some mobile devices depends on the programmes they contain (Brown and Medcalf, 2008).

This study focused on developing a text-based mobile application for review and preview of course content to enable students access their study materials on their mobile phones/handsets beyond the face-to-face learning environment. It was also to determine what mobile handsets or phones would be useful with the mobile application for students to access study materials in distance learning. Furthermore, the researcher wanted to find out whether there existed a statistically significant difference between the use of the mobile application on mobile handsets in accessing study materials and the short messaging service (SMS) mode of lesson delivery.

To Kukulska-Hulme and Traxler (2005), the most significant attributes of mobile technologies is their ability to support learning that is more situated, practical and contextualized within specific domains and to support the creation and use of more up-to-date and authentic content.

The objective of M-learning is to provide the learner the ability to assimilate learning anywhere and at any time (Crescente and Lee, 2011). The term covers: learning with portable technologies including but not limited to handheld computers, MP3 players, notebooks, mobile phones and tablets. M-learning focuses on the mobility of the learner, interacting with portable technologies, and learning that reflects a focus on how society and its institutions can accommodate and support an increasingly mobile population. Using mobile tools for creating learning aides and materials become an important part of informal learning (Crescente and Lee, 2011).

Wagner (2005) opined that evidence of the widespread adoption of mobile wireless technology such as cell phones, personal digital assistants (PDAs), laptop computers, and MP3 players, is irrefutable. Current mobile technologies (especially wireless) - frequently referred to as third generation (3G) - provide an unprecedented opportunity for inexpensive and beneficial computing power for learners (Hill \& Roldan, 2005; Wagner, 2005). Wagner (2005) then asks why, with the continuing expansion of wireless networks and improved capacity portable electronic devices, this mobility should not apply to learning. Keegan $(2002,2005)$ agrees with the views of Wagner and declares that the future of distance education is wireless communication and noting that there has never been a technology that has penetrated the world with the depth and rapidity of mobile telephony. He claims that the challenge for distance educators is to accept this fact and to now develop pedagogical environments for mobile devices.

Hosmer, Jeffcoat, Davis and McGibbon (2011) explained that new mobile technology, such as hand-held cellular based devices, is playing a large role in redefining how we receive information. The recent advances in mobile technology are changing the primary purpose of mobile devices from making or receiving calls to retrieving the latest information on any subject. Mobile learning can provide support that enhances training in a corporate business or other classroom environment. The mobile phone (through SMS notices) can be used especially for distance education or with students whose course requires them to be highly mobile and in particular to communicate information regarding availability of assignment results, venue changes and cancellations.

Significantly, mobile devices are innovative because they exceed the boundaries of the physical motionlessness of classrooms and lecture halls and their associated modes of communication, that is, they do not have to be confined to one particular place in order to be effective. According to Wagner (2005), the vision of mobile learning presented by the majority of authors currently writing in the field is that it seeks to enable 'anywhere, anytime, and any device' portable and personalized learning; it will facilitate communication, collaboration, and creativity among participants in authentic and appropriate contexts of use. In some respects, this is perceived as a revolution of 'just-in-time' and 'just-for-me' information delivery.

Just as the processing power and capabilities for PCs is growing, that for mobile phones is also growing. With dropping prices and increasing utility, it is almost a foregone conclusion that not too far into the future all students will have a cell phone, quite possibly built right into their clothing (Prensky, 2008). Even though, the prices of mobile handsets are dropping in other parts of the world that of Ghana is on the ascendency due to the exchange rate of the dollar.

In the attempt to look into the technological advancement in ubiquitous computing, Liu and Milrad (2010) stated that students in a one-to-one learning scenario used handheld devices fitted with wireless communication capabilities to support various learning activities. According to them, the usage of handheld devices contributes to the creation of new patterns of interaction and classroom dynamics that may support learning in many ways. They connect the classroom to the outside world, facilitate social learning process, and contextualise the learning experience.

The changes in the delivery of lessons over the years have actually brought in a new dimension in learning. One of such ways is the use of mobile devices in learning based on one-to-one learning activities. It can be argued that the pervasiveness of mobile technologies is generating a distinct culture where learners repeatedly use mobility and awareness of their immediate context as starting points for keeping social contact alive, accessing fresh content, getting local information and becoming visible as creators and producers of content (Kukulska-Hulme, 2010). 
Several benefits are associated with mobile learning. The fact cannot be denied that mobility allows teaching and learning to extend beyond the traditional classroom. In the case of distance learning, users of portable devices can break the chain of the home computers. Mobile learning also encourages collaborative, accessible and integrated learning which goes beyond the classroom (Nyiri, 2002; Wagner, 2005; Prensky, 2008; Liu \& Milrad, 2010).

\section{Methodology}

The mixed methods research design was employed in conducting the study. The design is a procedure for collecting, analysing and mixing both quantitative and qualitative research and methods in a single study to understand a research problem. It involves experimental design, qualitative and quantitative data and statistical analysis (Creswell, 2012). The current study involved designing a mobile application which enabled students to download study materials on to their mobile handsets. The application developed had a log in page that provided access to the main page where students could request for study materials based on their choice of subject. The application also has a database for courses that are mostly accessed and downloaded as well as recently accessed or downloaded courses.

A WAMP Server was used to hold the application and database as well as to serve all mobile phones that requested for the application. Figure 1 shows the relationship between the application and the other components in the setup of the system.

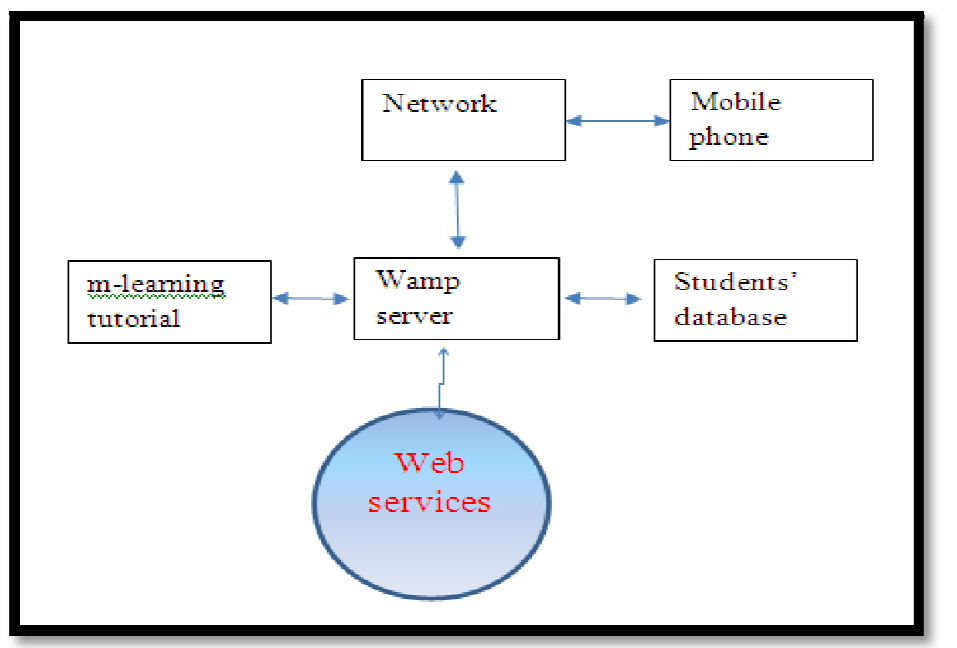

Figure 1: Relationship between the Application and the Other Components in the System Setup

The application was installed a WAMP Server that runs on one of the wireless network computers providing the web services. The WAMP Server has mobile learning tutorials loaded onto it. The study materials were in Portable Document Format (pdf), Word Processing applications format like MS Word, PowerPoint Format (ppt), spreadsheet format like MS Excel Format (xls) as well as Joint Picture Experts Group format (jpeg) and Tagged Image File format (tif). The application also has students' database which is used to authenticate who has requested for the tutorial services. Students used their mobile phones to access and request for study materials from the system and the system also responded within a short period with the appropriate material. Students download the materials on their phones and use the materials for study anytime, anywhere and at will, no matter the location and time. Hence, just upon getting hold on the phone, students begin to learn.

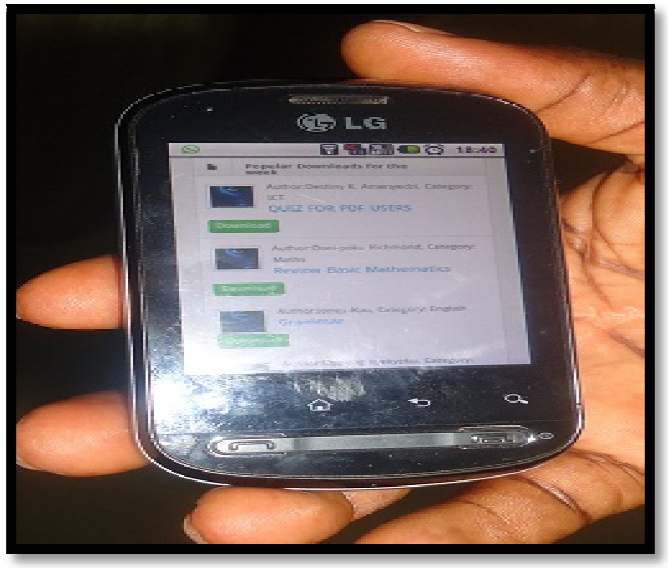

Figure 2: The Interface of the Application as Viewed from an LG-P350 Mobile Phone by One of the Students 
The application requests from a user to provide username and password before allowing the user access into the system. The user after providing the needed password is presented with a page that requires him/her to request for tutorials based on categories provided. The user also has the benefit of viewing popular downloads from the system as well as recently uploaded files. There is a search bar for the user to type the name of the category of materials he/ she needs. All that the user needs to do is to connect to the system and use a web browser to gain access to these tutorials.

The population for the study was the 298 post-diploma degree students pursuing distance education at the St Francis College of Education Centre, Hohoe of the University of Education, Winneba Centre for Distance Education. Out of the 298 students, 40 students were selected for the study at random. The simple random sampling technique was use in selecting the sample.

The study material was also sent through the use of Short Messaging Service (SMS) to the forty (40) students selected for the study. The objective of sending the study material through SMS was to determine whether statistically significant differences existed in the time taken to receive the material between the mobile application developed and SMS.

A t-test was run to determine whether a statistically significant difference existed between the time used to receive study materials from the mobile application and the SMS.

Four classes of mobile phones (LG-P350 (L), Samsung galaxy pocket (S), Nokia C3(N) and Tecno N3/ P3 (T)) were used by students to access $184 \mathrm{~kb}$ material from the application. Five, ten, twenty and forty of each the phones were used concurrently at a time to access the $184 \mathrm{~kb}$ material from the application.

Figure 3 shows the four types of phones used and their download time in accessing the $184 \mathrm{~kb}$ material from the application.

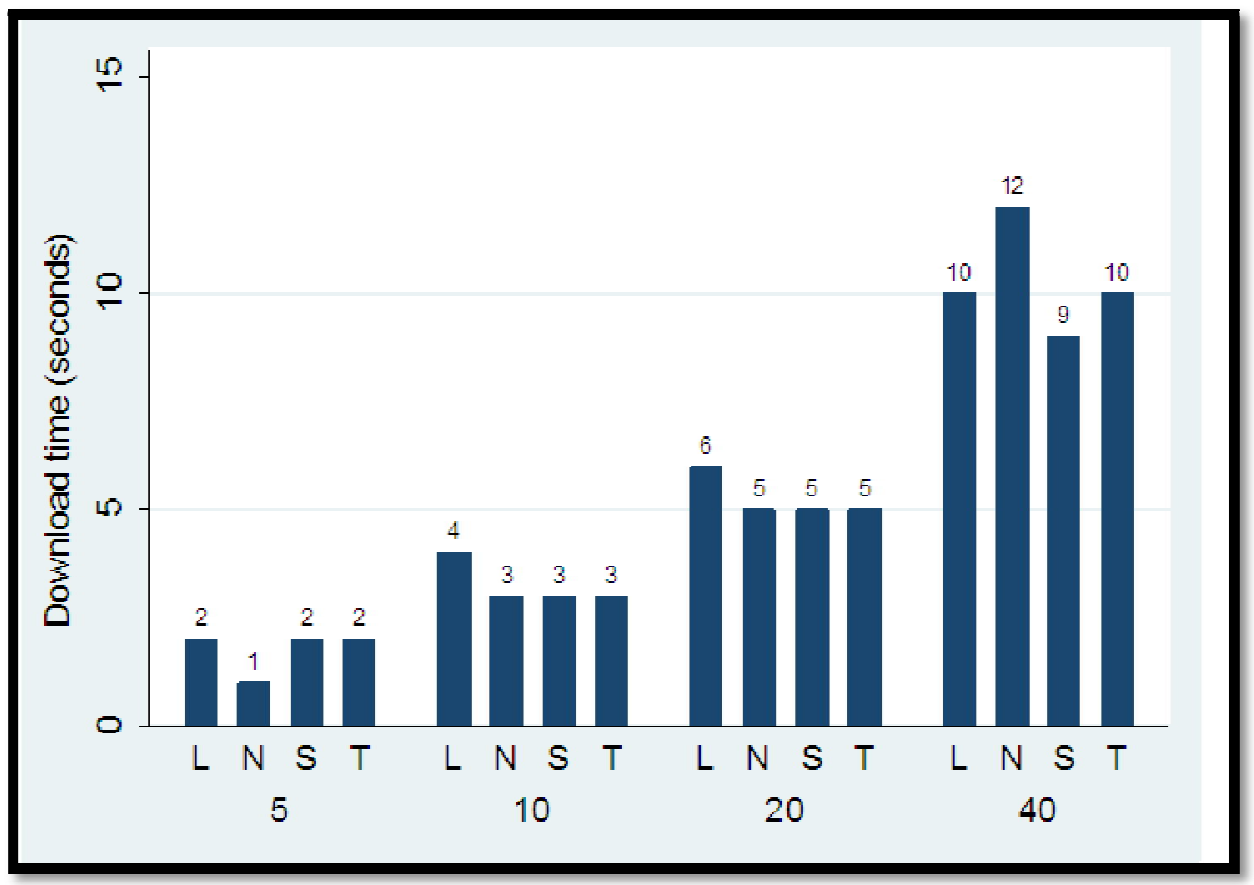

Figure 3: Classes of Mobile Phones and the Download Time

Key: L =LG-P350; N =NOKIA C3; S = SAMSUNG; T =TECNO N3/ P3

\section{Results}

Figure 3 shows that when five each of the four types of phones (LG-P350, Nokia C3, Samsung galaxy pocket, and Tecno N3/ P3) were used concurrently to access the $184 \mathrm{~kb}$ material from the application, their download times were 2 seconds, 1 second, 2 seconds and 2 seconds respectively. It was only the Nokia C3 phones that downloaded the material in a second; the rest of the phones had their download completed in 2 seconds respectively. When ten each of the four types of phones (LG, Nokia C3, Samsung, and Tecno N3/ P3) were used in accessing the material from the server, their download time was 4 seconds, 3 seconds, 3 seconds and 3 seconds respectively. It was only the LG phones that had a download time of 4 seconds; the download time for each of the rest of the phones was 3 seconds. On the other hand, the download time when 20 each of the four classes of phones were used in downloading the material were 6 seconds for the LG phone and 5 seconds for the Nokia C3, Samsung and Tecno N3/ P3 respectively. Finally, when 40 each of the four types of phones were employed concurrently in downloading the $184 \mathrm{~kb}$ material from the application, the download time for LG-P350 phones was 10 seconds, Nokia C3 12 seconds, Samsung 9 seconds and Tecno N3/ P3 10 seconds. These data showed that as the number of phones accessing a material from the application increases, the download time also increases. It can, therefore, be concluded that the four classes of mobile phones used for the study were useful in accessing materials from the mobile application for study in distance education. This means that students having study materials on their mobile handsets can learn anytime they wish. This will tremendously increase the time for learning hence will have serious impact on their academic achievement. This finding has shown that students in higher institutions who are pursuing distance education have classes of mobile devices that can facilitate their learning on the go. 
However, it was found that even though the Nokia C3 mobile phones could access and download the study materials, it could not open the files due to the fact that it could not support the type of file format used for the materials.

\subsection{Hypothesis Testing}

Hypothesis 1: There is no statistically significant difference between the time taken to download study materials from the application developed and through SMS.

Table 1 shows data on the difference between the time taken to download study materials from the application developed and through SMS.

\begin{tabular}{|c|c|c|c|c|c|c|}
\hline Access Mode & N & Mean & $\begin{array}{c}\text { Standard } \\
\text { Deviation }\end{array}$ & Df & T & Significant \\
\hline Application & 40 & 4.38 & 0.490 & 39 & 55.791 & 0.000 \\
\hline SMS & 40 & 15.65 & 7.721 & & & \\
\hline
\end{tabular}

Table 1: Difference between Time Taken to Download Study Material from the Application Developed and Through SMS Source: Field Data, 2012

The analysis shown in Table 1 indicated that the means for the time taken by the various mobile phones to download the study materials from the application (WAP) and through the use of the SMS are 4.38 and 15.65 respectively. Their respective standard deviations are 0.490 and 7.721. At an alpha level of 0.05 , the difference between the time taken to download the study materials with the application and the SMS was found to be statistically significant, $\mathrm{t}(39)=55.791$, $\mathrm{p}<0.0001$. Thus, the hypothesis that there is no statistically significant difference between the time taken to download study materials from the application developed and through SMS is rejected. Therefore, a significant difference existed between the time taken to download study materials from the application developed and through SMS.

\section{Key Findings}

The following are some key findings from the study. It was revealed that students used LG-P350, Nokia C3, Samsung galaxy pocket and Tecno N3/ P3 mobile handsets to access study material from the application. It was observed that these mobile phones used had wireless connections. This finding has shown that students in higher institutions who are pursuing distance education have classes of mobile devices that can facilitate their learning on the go. This finding collaborates the research finding of Corbeil and Valdes-Corbeil (2007). In their research, Corbeil and Valdes-Corbeil found that out of mobile learning devices own by students in higher institutions included cell phones and laptops, the cell phones had 93\% while laptops had 92\%. They concluded that these cell phones enhance the use of mobile learning in education.

Another revelation was that students used different time periods in getting to the target and getting responses from the target. The revelation was that as the number of individuals accessing the $184 \mathrm{~kb}$ material from the WAMP server increases, the download time also increases. Students used 1 to 2 seconds to hit the target when five each of the mobile phones were used at a time. They used 3 to 4 seconds to get their responses when ten of each type of the phones was used concurrently. When twenty of each type of the mobile phones was used at a time to access the $184 \mathrm{~kb}$ material, the download time was five to six seconds. However, when forty of the phones were used at a time, the download time was 9 to 12 seconds. Hence, as the number of mobile handsets increased, the download time also increased.

The study again revealed that Samsung galaxy pocket and Tecno N3/ P3 are powerful tools which can support any mobile learning application. However, Nokia C3 has to be improved upon in order to accept any format of the files uploaded on the application system.

With the use of the SMS in sending to students' study materials, six (6) students representing $15 \%$ were able to receive the material in 32 seconds while $5(12.5 \%)$ students received the material in 19 seconds. Nine (9) students representing $22.5 \%$ took 15 seconds to receive the text message while 14 students representing $35 \%$ took only 9 seconds. The rest of the 6 students (15\%) took 13 seconds to receive the message.

It was found that the sizes of the files for the SMS as compared to those downloaded with the mobile application were relatively small. The files uploaded in the mobile application were up to $184 \mathrm{~kb}$ but the SMS files were between $4 \mathrm{~kb}$ to $28 \mathrm{~kb}$. It was also found that some of the phones could receive the file within a short time but they took a very long time to deliver the same message to another phone.

However, it was found that the different time periods used in hitting the target and getting the responses was due to the various types of mobile phones used.

\section{Conclusions and Recommendation}

The results of the study showed that the mobile application developed to provide students with quick access to study materials worked effectively. The mobile application was compatible with four classes of mobile phones or handsets used by participants during the study. These mobile phones were LGP350, Nokia C3, Samsung galaxy pocket and Tecno N3/ P3.

However, it was discovered that students used different time periods in getting to the target and receiving responses from the target when the number of requests for the material from the application increased. The hypothesis testing revealed that a significant difference existed between the time taken to download study material from the mobile application developed and the use of SMS in sending the material. 
In a nutshell, the study established that LG-P350, Nokia C3, Samsung galaxy pocket and TecnoN3/ P3 mobile phones could be used to access material from the mobile application developed. It can, therefore, be concluded that mobile phones or handsets can be used in distance education in accessing study materials with the mobile application developed.

It is recommended that stakeholders in higher education in Ghana see to it that this application and other designed by earlier researchers are used for distance learners for the maximum benefit.

\section{References}

i. Brown, J. \& Metcalf, D. (2008). Mobile Learning Update. New York: The MASIE Center and Learning Consortium.

ii. Crescente, M. L. \& Lee, D. (2011). Critical issues of M-Learning: design models, adoption processes, and future trends. Journal of the Chinese Institute of Industrial Engineers 28 (2), 111-123.

iii. Creswell, J. (2012). Educational research: Planning, conducting and evaluating quantitative and qualitative research. ( $4^{\text {thed.). }}$. Upper Saddle River, NJ: Pearson Education.

iv. Corbeil, J. R. \& Valdes-Corbeil, M. E. (2007) Are you ready for Mobile learning. EDUCAUSE QUARTERLY

v. Hill, T. R. \& Roldan, M. (2005). Toward third generation threaded discussions for mobile: Opportunities and challenges for ubiquitous collaborative environments. Information Systems Frontiers, 7 (1), 55 - 70.

vi. Hosmer, C., Jeffcoat, C., Davis, M. \& McGibbon, T. (2011). Use of Mobile Technology for Information Collection and Dissemination. Data \& Analysis Center for Software, March 2011.

vii. Keegan, D. (2002). The future of learning: From elearning to mlearning. Ericsson

viii. Keegan, D. (2005). "The incorporation of mobile learning into mainstream education and training", in Proceedings of the 4th World Conference on MLearning (MLearning: 2005), SA, 25-28 October

ix. Kukulska-Hulme, A. (2010) Learning cultures on the move: Where are we leading? Educational Technology \& Society 13(4), 4-14.

x. Liu, C.C., \& Milrad, M. (2010). Guest Editorial-One-to-One learning in the mobile and Ubiquitous computing age. Educational Technology \& Society 13(4), 1-3.

xi. Muyinda, P. B. (2007). MLearning: pedagogical, technical and organizational hypes and realities. Campus-Wide Information systems, Vol.24, 2, 97-104.

xii. Nyiri, K. (2002) Towards a philosophy of M-Learning. Paper Presented at the IEEE International Workshop on Wireless and Mobile Technologies in Education (WMTE 2002), August 29-30, 2002, Teleborg Campus, Växjö University, Växjö, Sweden. Accessed 30/ 08/ 2012

xiii. Prensky, M. (2008). What can you learn from a Cell phone? Almost anything! Available online at http:/ / www.innovateonline.info/ index.php?view=article\&id=83. Accessed on 22/ 10/ 2012.

xiv. Ryu, H., \& Parsons, D. (2008). Innovative Mobile Learning: Techniques and Technologies. (ISBN: 978-1-60566062-2).

xv. Traxler, J. (2003). Mobile learning - evaluating the effectiveness and the cost. Proceedings of MLEARN 2003: Learning with Mobile Devices. London, UK: Learning and Skills Development Agency.

xvi. Traxler, J., \& Kukulska-Hulme, A. (2005). Evaluating Mobile Learning: Reflections on Current Practice. Proceedings of mLearn 2005. Retrieved March 27, 2012, from http:/ / www.mlearn.org.za/ papers-full.html.

xvii. Wagner, E. (2005) Enabling Mobile Learning. Educause Review, 40(3), 40-53. 